\title{
Quantitative analysis of cadmium in rice roots based on LIBS and chemometrics methods
}

\author{
Wei Wang ${ }^{1 \dagger}$, Wenwen Kong ${ }^{1,3+}$, Tingting Shen ${ }^{1}$, Zun Man ${ }^{1}$, Wenjing Zhu ${ }^{2}$, Yong He ${ }^{1,4}$ and Fei Liu ${ }^{1,4^{*}}$ (1)
}

\begin{abstract}
Background: Excessive cadmium can damage cell structure, inhibit enzyme activity, and affect metabolic process, thus, leading to decline of rice yield and quality. Root is an important organ of crops, the detection of cadmium in root is essential for limitation of cadmium in rice grains.

Results: In this study, laser-induced breakdown spectroscopy (LIBS) was applied for cadmium quantitative analysis. Pretreatment methods, including median absolute deviation, wavelet transform, area normalization, were used to improve spectral stability. Scanning electron microscope and energy-dispersive X-ray spectrometer (SEM/EDS) was first used to analyze ablation pit surface characteristics and the results showed significant positive correlation with spectral lines of Cd II 214.44, Cd II 226.50 and Cd I $228.80 \mathrm{~nm}$. Univariable models of spectral lines showed that three Cd spectral lines have good prediction for cadmium. Fitting methods including linear, logarithmic, and polynomial were used to propose characteristic input variables, and univariable models based on variable of polynomial fitting of $I_{214.44 \mathrm{~nm}}$ have achieved the best effect $\left(R_{p}=0.9821\right.$ and RMSEP $\left.=31.1 \mathrm{mg} / \mathrm{kg}\right)$. Besides, partial least squares regression (PLSR), least squares support vector machine (LS-SVM) and extreme learning machine (ELM) were used for multivariate analysis. Compared with univariate analysis, ELM model based on the full spectrum $\left(R_{p}=0.9896\right.$ and RMSEP $=26.0 \mathrm{mg} / \mathrm{kg}$ ) had more advantages for cadmium detection.

Conclusion: Compared with traditional methods (150 min), the quantitative detection method based on LIBS technology (less than $5 \mathrm{~min}$ ) greatly reduces the detection time of heavy metals. The results showed that LIBS has proved to be a reliable method for quantitative detection of cadmium in rice roots. The research can provide theoretical support for timely detection of heavy metals in crop and food production.
\end{abstract}

Keywords: Rice root, Cadmium, Laser-induced breakdown spectroscopy, Fitting methods, Extreme learning machine

\section{Background}

Rice is the main grain crop in China. Compared with other crops, rice has strong absorption of cadmium. Excessive cadmium can hinder cell division, damage cell structure, inhibit enzyme activity, and affect metabolic process, thus, leading to decline of rice yield and quality [1-3]. Cadmium is a non-essential element of human body $[1,4,5]$. Consumption of cadmium-contaminated

\footnotetext{
*Correspondence: fliu@zju.edu.cn

tWei Wang and Wenwen Kong contributed equally to this paper ${ }^{1}$ College of Biosystems Engineering and Food Science, Zhejiang University, 866 Yuhangtang Road, Hangzhou 310058, China Full list of author information is available at the end of the article
}

rice for a long time seriously harms human health [6]. Cadmium can damage human kidney function, hinder bone metabolism, and cause various bone diseases [7, 8]. World Health Organization (WHO) recommends no more than $68 \mu \mathrm{g}$ of cadmium per person per day. Due to the consideration of protecting human body from cadmium, countries have established some mandatory standards to limit cadmium content in food. In accordance with the National Food Safety Standards for Contaminants in Foods (GB 2762-2012), the cadmium content in food ranges from 0.005 to $2 \mathrm{mg} / \mathrm{kg}$, and its content in rice grains should not exceed $0.2 \mathrm{mg} / \mathrm{kg}$. Clemens et al. [9] found that there were three processes from root absorption to cadmium accumulation in grain: root
Springer Open

(c) The Author(s) 2021. This article is licensed under a Creative Commons Attribution 4.0 International License, which permits use, sharing, adaptation, distribution and reproduction in any medium or format, as long as you give appropriate credit to the original author(s) and the source, provide a link to the Creative Commons licence, and indicate if changes were made. The images or other third party material in this article are included in the article's Creative Commons licence, unless indicated otherwise in a credit line to the material. If material is not included in the article's Creative Commons licence and your intended use is not permitted by statutory regulation or exceeds the permitted use, you will need to obtain permission directly from the copyright holder. To view a copy of this licence, visit http://creativeco mmons.org/licenses/by/4.0/. 
absorption, xylem transport, and phloem migration to grain. Li et al. [10] found that cadmium content in grain was largely restricted by root absorption capacity. The transfer coefficient of cadmium in root-stem, stem-leaf, leaf-seed and stem-seed decreased successively. As front part, root is an important organ that affects accumulation and transportation of cadmium in rice grains $[11,12]$. Therefore, the detection of cadmium in rice roots is of great significance to limit cadmium content in rice.

At present, atomic absorption spectroscopy (AAS), inductively coupled plasma optical emission spectrometer (ICP-OES) and inductively coupled plasma with mass spectrometer (ICP-MS) are widely used for heavy metal detection [13-16]. Traditional multi-element analysis methods mean lengthy sample preparation and complex chemical experiments. They have disadvantages such as large sample loss, complicated operation, high cost, and time-consuming. It cannot meet requirements of low cost, fast response and accurate detection in precision agriculture $[17,18]$. As an element analysis method, laser-induced breakdown spectroscopy (LIBS) technology was proposed by the David Cremers research group of Los Alamos National Laboratory in the United States in $1962[13,19]$. Compared with commonly used chemical detection approaches, LIBS has the characteristics of rapidity, batch, microdamage, multi-element simultaneous analysis and no complex pretreatment [20-22]. Recently, LIBS has been used for rapid detection of elements in crops, which has significance for food security and environmental pollution. Yang et al. [23] prepared samples by adding heavy metal reagents to the standard rice and used LIBS coupled with ultrasound-assisted extraction to achieve the rapid detection of toxic elements $(\mathrm{Cd}$ and $\mathrm{Pb})$ in rice. Liu et al. [24] soaked rice in the copper solution to prepare copper-contaminated rice samples and applied LIBS for quantitative analysis of copper in three kinds of rice, the results showed that LIBS could be considered as a useful tool for copper detection. Jabbar et al. [25] detected the composition of nutrient elements in different parts (root, stem and seed) of the rice plant using LIBS, and determined their weighted concentration. Peng et al. [26] investigated the influence of parameters in dual-pulse LIBS method to predict chromium content in rice leaves and provided a fast approach for toxic elements prediction in rice leaves. However, due to the difficulty of obtaining the real plant root samples contaminated with heavy metals and the complexity of the plant matrix effects, few studies have focused on the application of LIBS technology in the high-precision quantitative detection of heavy metals in roots. In agricultural production, cadmium in the environment is absorbed by rice roots from the soil and then transferred to the above-ground parts, resulting in the accumulation of cadmium in rice grains. As a bridge between external cadmium pollution and above-ground rice grains, the cadmium in rice roots directly affects the accumulation of cadmium in grains. Based on the advantages of LIBS technology that can achieve batch processing and rapid detection, we used real rice roots contaminated with cadmium as samples to research rapid quantitative detection of cadmium in rice roots based on LIBS and chemometrics methods.

This study preliminarily introduces a method for quantitative detection of cadmium in rice roots using LIBS. The specific content includes: (1) to pretreat raw spectra with MAD, WT and area normalization and analyze LIBS spectra to determine Cd spectral lines; (2) to apply SEM/ EDS to reflect the surface characteristics of ablation pits, then analyze the correlation between $\mathrm{Cd}$ spectral lines and SEM/EDS; (3) to establish univariate models based on Cd spectral lines; (4) to propose characteristic input variables about $\mathrm{Cd}$ and establish univariate models based on variables; (5) to establish multivariate models and compare them with univariate models to determine the optimal quantitative model for cadmium in rice roots.

\section{Materials and methods}

\section{Sample preparation}

The rice variety selected in the experiment was Xiushui 134, which was a single-season conventional late japonica rice widely cultivated in Zhejiang Province, China. Rice seeds with full granule and consistent size were selected and sterilized with $1 \% \mathrm{NaClO}$ solution for $20 \mathrm{~min}$, washed several times with distilled water, soaked in dark environment for $48 \mathrm{~h}$. The soaked seeds were placed in a seedling tray and placed in an incubator (temperature: $35{ }^{\circ} \mathrm{C}$, humidity: $85 \%$ ), sprouting for $2-3$ days. After the rice seeds were germinated, they were transplanted to the sponge in the seedling tray and placed in an artificial climate chamber (duration of day mode: $14 \mathrm{~h}$, temperature: $30{ }^{\circ} \mathrm{C}$, humidity: $85 \%$, light intensity: $225 \mu \mathrm{mol} \mathrm{m}{ }^{-2} \mathrm{~s}^{-1}$; duration of night mode: $10 \mathrm{~h}$, temperature: $30^{\circ} \mathrm{C}$, humidity: $85 \%$ ). During cultivation, nutrient solution of rice was prepared according to international rice nutrient solution formula, with $\mathrm{pH}$ value of 5.3-5.6. As rice enters tillering stage of growing season, it begins to add a certain concentration of heavy metals to the nutrient solution. $\mathrm{CdCl}_{2}$ reagent was used to prepare cadmium solution. Referring to the existing literature, $\mathrm{Cd}^{2+}$ concentration gradient was $0 \mu \mathrm{M}(\mathrm{CK}), 5 \mu \mathrm{M}, 25 \mu \mathrm{M}, 50 \mu \mathrm{M}$ and $100 \mu \mathrm{M}$ [27, 28].

After 10 days, 20 days and 30 days, rice roots at different concentrations were collected as samples. In total, 15 rice root samples with different concentrations were obtained, namely Day10-CK, Day10-5, Day10-25, Day10-50, Day10-100, Day20-CK, Day20-5, Day20-25, 
Day20-50, Day20-100, Day30-CK, Day30-5, Day30-25, Day30-50 and Day30-100. First rice roots were washed with tap water and distilled water, respectively, to remove impurities on the surface of sample, then immersed them in EDTA-2Na solution for $60 \mathrm{~min}$ to remove heavy metals that may remain on samples, and finally washed again with distilled water as the experimental sample. To obtain dry root samples, the fresh rice roots were dried to a constant weight in an oven (temperature: $60{ }^{\circ} \mathrm{C}$, time: $72 \mathrm{~h}$ ). The dried roots were ground into powder using grinding instrument (JXFSTPRP-48, Shanghaijingxin, Shanghai, China). $100 \mathrm{mg}$ of powder was weighed from each gradient of the sample. The tablet machine (YLJ-20T, Guoyan, Hebi, China) was used to compress the powder into tablets of $10 \mathrm{~mm} \times 10 \mathrm{~mm} \times 1 \mathrm{~mm}$ at a pressure of $60,000 \mathrm{~N}$ for $20 \mathrm{~s}$, which were used as samples to be tested. Four tablets were prepared for each gradient of the sample. In total, 60 root tablets were obtained for collecting LIBS spectral data.

\section{LIBS instrumentation}

The structural diagram of the LIBS system is shown in Fig. 1. As a laser source, Q-switched Nd:YAG nanosecond pulsed solid-state laser (Vlite-200, Beamtech Optronics, Beijing, China) is used to generate laser pulses, with a repetition frequency of $1-10 \mathrm{~Hz}$, a spot diameter of $7 \mathrm{~mm}$, and a pulse width of $8 \mathrm{~ns}$. In the experiment, monochromator and ICCD camera are combined to obtain high-resolution spectral information in a specified short-wave segment. The monochromator with the wavelength range of $180-850 \mathrm{~nm}$ (SR-500i-A-R, Andor, Belfast, UK) is used as a spectrometer to separate the signals generated by the plasma transition. The central wavelength is adjusted to limit the range of collected spectra. In the experiment, the central wavelength was set at $220.53 \mathrm{~nm}$, and the spectra were collected in the range of 210.01$231.00 \mathrm{~nm}$. The ICCD detector of IStar 340T series (time gate width: $5 \mathrm{~ns}$, wavelength range: $180-850 \mathrm{~nm}$ ) is adopted to convert the optical signal into electric signal. In addition, a digital delay pulse generator with a time resolution of 5 ps and a controllable time range of 0-2000 ns (DG645, Stanford Research Systems, California, USA) can control the timing of lasers and ICCD detectors in real time. The $\mathrm{X}-\mathrm{Y}-\mathrm{Z}$ stage with a repeatability of $5 \mu \mathrm{m}$ and a maximum stroke of $50 \mathrm{~mm}$ (Zolix, Beijing, China) can realize real-time movement of samples. The working mode of different pulse outputs is realized by the optical path system built by our own experimental team. Experimental parameters of the LIBS system such as laser pulse wavelength and energy, spectrometer delay time, ICCD gate width and gain of LIBS instrument are all key factors that affect the accuracy of the collected spectral data. For acquisition of a better signal-to-noise ratio (SNR), the parameters used in the experiment are as follows: $\lambda=532 \mathrm{~nm}$, energy $=60 \mathrm{~mJ}$, delay $=1 \mu \mathrm{s}$, gate width $=10 \mu \mathrm{s}$, and gain $=1500$. With the help of $\mathrm{X}-\mathrm{Y}-\mathrm{Z}$ stage, $4 \times 4$ array was set as the ablation path, where the distance between each row and each column is $2 \mathrm{~mm}$. Then, 16 positions on the sample were collected for spectrum, which are evenly distributed on each sample. To reduce point-to-point fluctuations of laser, each position was cumulatively ablated 5 times by laser with repetition rate of $1 \mathrm{~Hz}$. A single spectrum was obtained at each position, in which the spectrum was the accumulation of 5 ablations. As a result, 16 ablation pits were generated on each sample, and the average spectra of 16

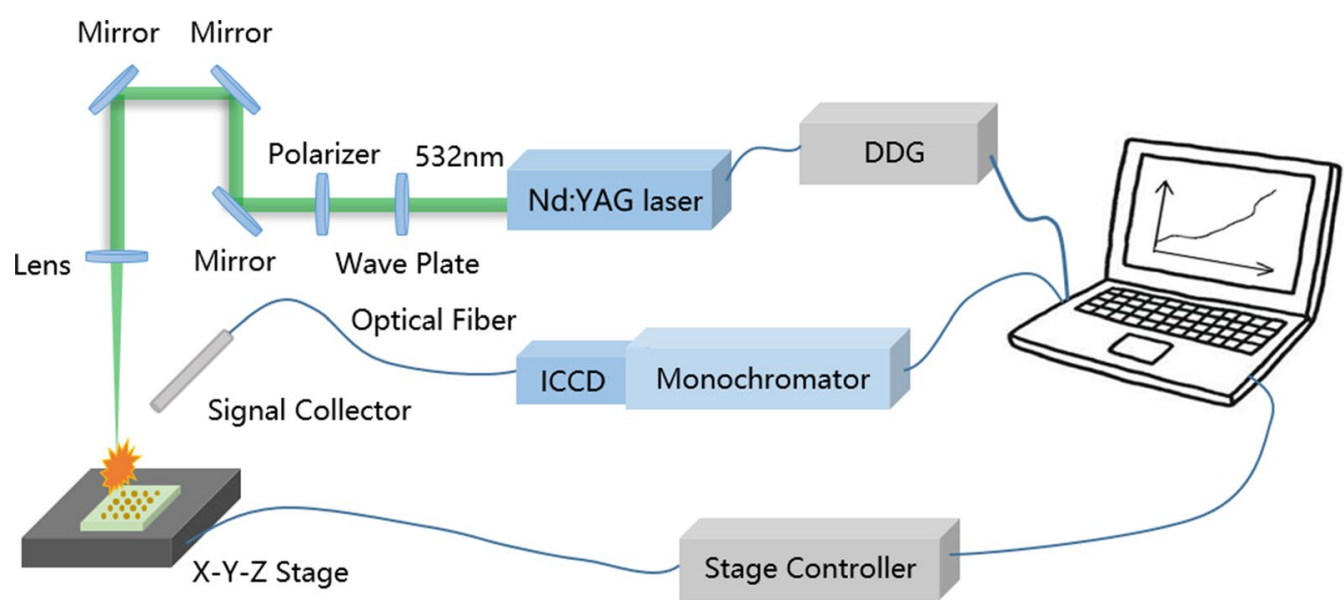

Fig. 1 Structural diagram of the LIBS system 
ablation pits obtained was taken as the LIBS data of the sample.

\section{Reference method ICP-OES instrumentation}

In the experiment, the reference cadmium content in rice roots which was used to achieve quantitative analysis of heavy metal was determined using inductively coupled plasma optical emission spectrometry (ICP-OES). Before detection, samples need to be pretreated with microwave digestion method. The specific experimental steps are as follows. The root tablets from which spectra have been collected were reground into powder. Rice root samples of a certain mass were weighed from each sample and put into Teflon digestion tube, and its mass was recorded. Then, add $5 \mathrm{~mL}$ of $65 \%$ nitric acid and $1 \mathrm{~mL}$ of $30 \%$ hydrogen peroxide to the digestion tube, and put it in the microwave digestion instrument (MARS 6, CEM, USA) for digestion. After digestion process, the digestion tubes were placed on electric heating board to remove acid from the sample. When the volume of residual liquid in digestion tube was less than $0.5 \mathrm{~mL}$, the acid removal was completed. Transfer the remaining liquid to a volumetric flask and dilute with deionized water to a $50 \mathrm{~mL}$ scale. Then, the solution is used for the determination of $\mathrm{Cd}$ content. After detection of ICP-OES (Optima 8000, PerkinElmer, Waltham, USA), we need to calculate the measured value according to the mass and volume of the sample, and finally get the Cd content in the root samples. In addition, the standard sample of citrus leaves (GBW10020, Beijing, China) was used as the control group to verify whether the experimental procedures met the standard operation. In the experiment, it took about 150 min to detect the $\mathrm{Cd}$ content in a root sample using ICP-OES.

\section{SEM/EDS technology}

SEM/EDS used in the experiment was Phenom XL system (Phenom XL, Phenom-World BV, Eindhoven, Netherlands), which is an integrated scanning electron microscope (SEM) platform equipped with an energydispersive X-ray spectrometer (EDS). The low-vacuum technology in SEM of the system can effectively suppress charging effect, so the system can realize direct observation of rice root samples without spraying gold or carbon. The EDS uses a high-brightness CeB6 filament that excites a large number of $\mathrm{X}$-rays, enhances the signal, and improves the accuracy of elemental analysis. Phenom XL system enables surface microscopic observation of nanoand submicron samples with diameters less than $100 \mathrm{~nm}$ and magnifications up to 100,000 times. The EDS software can assess the relative contribution of each detected element in the region of interest, expressed as a percentage [29]. In addition, the software can achieve a visual distribution of detected elements in the selected area.

\section{Data treatment}

During the LIBS ablation excitation process, complex matrix effect of the plant sample and parameters of the experimental instrument will directly affect the stability of the LIBS signal. This will cause the collected spectra to have problems such as abnormal values, background noise, point-to-point fluctuations, and baseline drift, which will lead to deviations in the results. For rice roots, it is difficult to completely eliminate these adverse effects by sample processing and instrument parameter adjustment. In this study, pretreatment methods, including abnormal elimination, wavelet transform and data normalization, were used to improve spectral stability without increasing complexity of operation.

Due to the randomness of plasma transition, there are usually some abnormal values in a series of spectra obtained at the same time, which will greatly affect accuracy. For obtained spectra, it cannot guarantee that each spectrum obtained has the characteristics of the sample. Median absolute deviation (MAD) was applied to remove outliers in this study [30]. Cd $226.50 \mathrm{~nm}$ was selected as the variable for outlier elimination, because the signal of Cd $226.50 \mathrm{~nm}$ had relatively high stability in the collected spectra. First, MAD and median of peak intensity at $226.50 \mathrm{~nm}$ were calculated. Then, the deviation between the peak value and the median value of each spectrum at $226.50 \mathrm{~nm}$ was calculated, respectively. If the difference was greater than 2.5 times of MAD, the spectrum would be regarded as an abnormal spectrum. When no abnormal spectrum is detected or less than $75 \%$ of the total spectrum is left, the program stops the loop [31]. As an effective denoising method, the wavelet transform (WT) using Daubechies 8 with decomposition scale 3 was applied to denoise spectra. For the spectra of the same sample, there are point-to-point fluctuations between single spectrum. These fluctuations have certain relationship with characteristics of some spectral lines. Spectral normalization can effectively reduce the fluctuation of point and point and improve the stability of spectra. Area normalization was used for pretreatment in this study.

To quickly and accurately detect the cadmium content in rice roots, LIBS technology was combined with chemometrics method to perform univariate and multivariate analyses of cadmium. The univariate analysis method is also called the calibration curve method. In this study, the cadmium content measured by ICP-OES was used as the reference value of model. The LIBS spectra and the reference value were fitted to establish univariate models. Different from univariate analysis, multivariate analysis 
is a commonly used method for information mining on a large amount of data, which can effectively deal with multicollinearity problem and establish linear regression model [32]. To compare the different results of model and determine the optimal effect of quantitative detection, a variety of modeling methods were used for comparison in the paper. For multivariate analysis, partial least squares regression (PLSR), least squares support vector machine (LS-SVM) and extreme learning machine (ELM) were used to establish quantitative models of Cd content in rice roots. To optimize the model performance, fivefold cross-validation is used to determine the optimal model parameters.

Before modeling, the rice root samples were divided into calibration set and prediction set at a ratio of 2:1. Arrange the samples of the cadmium concentrations. For every three samples, the second one is used for prediction, and the others for calibration. Therefore, 40 samples were selected as the calibration set and 20 samples as the prediction set.

\section{Performance evaluation}

In the process of LIBS modeling, some evaluation indexes can be used to evaluate the prediction effect of quantitative model. The correlation coefficient $(R)$ is used to evaluate the fitting effect of the model. Generally, the value of $R$ ranges from 0 to 1 . The value of $R$ is proportional to the fitting effect. That is, the larger the value of $R$, the better the fitting effect. $R_{\mathrm{c}}$ and $R_{\mathrm{p}}$, respectively, represent the calibration and prediction set correlation coefficients.
The root mean square error (RMSE) can represent the deviation between the chemical measurement value and the model prediction value, and can be used as a standard for measuring the model prediction result. RMSE includes root mean square error of calibration (RMSEC) and root mean square error of prediction (RMSEP). The RMSE value is proportional to the prediction error of the model. The smaller the RMSE value, the better the model modeling effect obtained.

\section{Results and discussion}

\section{Reference analysis of ICP-OES}

The reference content of cadmium in rice roots was shown in Fig. 2. Cadmium concentrations in 15 root samples ranged from 0 to $537.79 \mathrm{mg} / \mathrm{kg}$. The cadmium content in CK groups (Day10-CK, DAY20-CK, and Day30-CK) was 0 . For cadmium content, the samples of the $13 \mathrm{cad}-$ mium stress groups increased in the following order: Day10-5 $\rightarrow$ Day30-25 $\rightarrow$ Day30-5 $\rightarrow$ Day20-5 $\rightarrow$ Day10$25 \rightarrow$ Day10-50 $\rightarrow$ Day20-25 $\rightarrow$ Day10-100 $\rightarrow$ Day30$50 \rightarrow$ Day20-50 $\rightarrow$ Day20-100 $\rightarrow$ Day30-100.

\section{LIBS spectral analysis}

Referring to the National Institute of Standards and Technology (NIST), in the range of $210.01-231.00 \mathrm{~nm}$, there are three cadmium emission lines with good strength, namely, ionic emission line Cd II $214.44 \mathrm{~nm}$, ionic emission line Cd II $226.50 \mathrm{~nm}$, and atomic emission line $\mathrm{Cd}$ I $228.80 \mathrm{~nm}$, as shown in Table 1. The spectra of rice roots with different cadmium concentrations, including

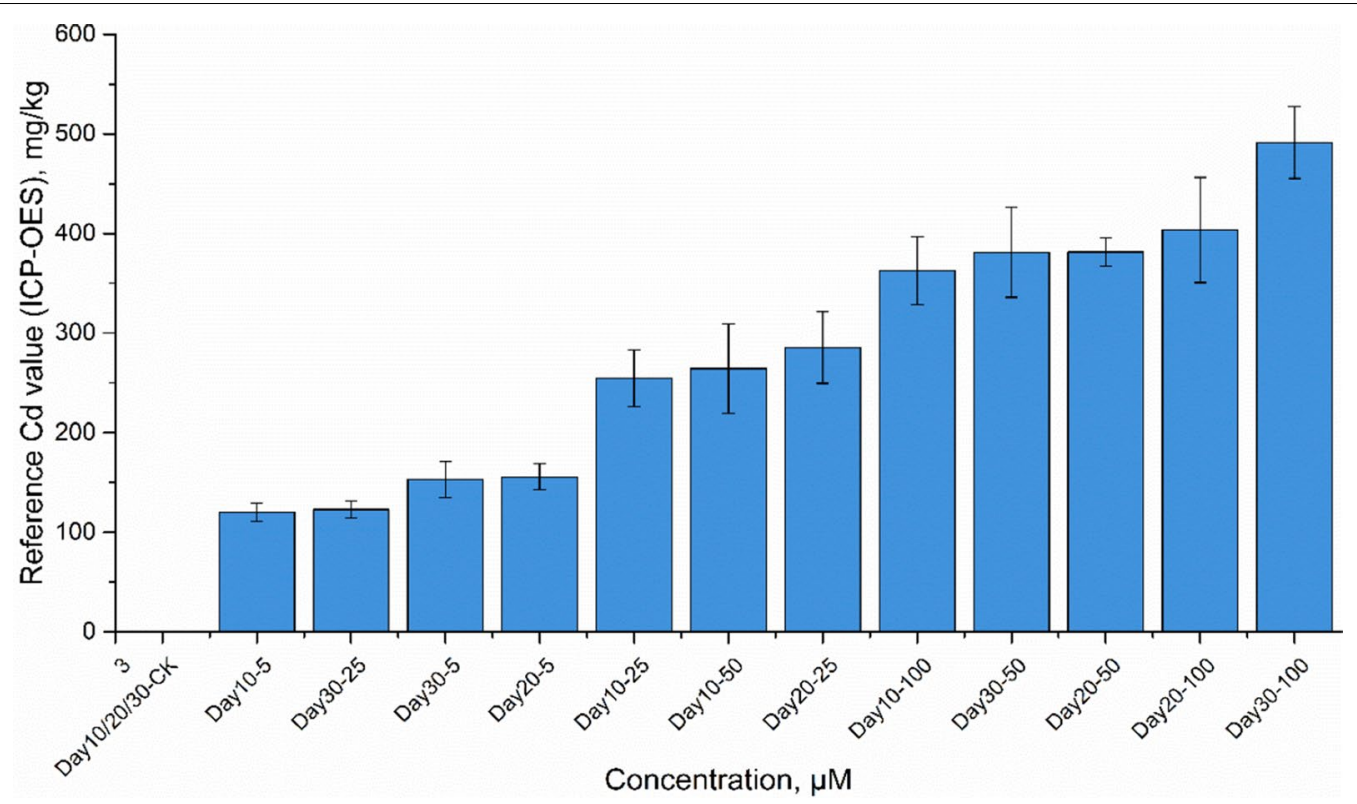

Fig. 2 Reference cadmium content in rice roots 
Table 1 Spectral properties of cadmium emission lines

\begin{tabular}{lllll}
\hline Ion & Wavelength $(\mathrm{nm})$ & Rel. Int. $^{\mathrm{a}}$ & $A_{\mathrm{ki}}\left(\mathrm{s}^{-1}\right)^{\mathrm{b}}$ & $E_{\mathrm{i}}-E_{\mathrm{k}}(\mathrm{eV})^{\mathrm{c}}$ \\
\hline $\mathrm{Cd}$ II & 214.43 & 1000 & $3.778 \times 10^{8}$ & $0-5.80$ \\
Cd II & 226.50 & 1000 & $3.177 \times 10^{8}$ & $0-5.48$ \\
Cd I & 228.80 & 1500 & $5.300 \times 10^{8}$ & $0-5.43$
\end{tabular}

a Rel. Int.: relative intensity of emission lines

b $A_{\mathrm{ki}}$ : transition probabilities

c $E_{\mathrm{i}}-E_{\mathrm{k}}$ : lower level and upper level energies of the transition

Day10-CK, Day10-5, Day10-25, Day10-50, Day10-100, Day20-CK, Day20-5, Day20-25, Day20-50, Day20-100, Day30-CK, Day30-5, Day30-25, Day30-50 and Day30100 , were collected by monochromator. In Fig. 3, the strongest intensities were observed at Cd II $214.44 \mathrm{~nm}$, Cd II $226.50 \mathrm{~nm}$, and Cd I $228.80 \mathrm{~nm}$, which are associated with cadmium. The average raw spectra of rice roots are shown in Fig. 3a. X-axis is wavelength, where the range is $210.01-231.00 \mathrm{~nm}$, and Y-axis is spectral intensity. Each spectral line is average spectrum of rice root samples in the same group. In this study, median absolute deviation (MAD), wavelet transform (WT), and area normalization were used to preprocess raw spectra. The average spectra after pretreatment are shown in Fig. 3b, where Y-axis is the spectral intensity after normalization. Compared with raw spectra, the background noise is reduced and the spectra are smoother after pretreatment.

The comparison of rice root spectral intensities with different cadmium concentrations at Cd II $214.44 \mathrm{~nm}$, Cd II $226.50 \mathrm{~nm}$ and Cd I $228.80 \mathrm{~nm}$ was shown in Fig. 4. Figure 4a, c, e, respectively, shows the spectral intensities of all samples in the range of 213.00$217.00 \mathrm{~nm}, 224.00-227.00 \mathrm{~nm}$ and $227.00-230.00 \mathrm{~nm}$. No significant $\mathrm{Cd}$ lines were detected in the CK group
(Day10-CK, Day20-CK and Day30-CK) at $214.44 \mathrm{~nm}$, $226.50 \mathrm{~nm}$ and $228.80 \mathrm{~nm}$. The reason was that there was no cadmium in the CK group, the cadmium content failed to reach the detection limit of instrument. According to the specific concentration sequence (Day10-5 $\rightarrow$ Day30-25 $\rightarrow$ Day30-5 $\rightarrow$ Day20-5 $\rightarrow$ Day10$25 \rightarrow$ Day10-50 $\rightarrow$ Day20-25 $\rightarrow$ Day10-100 $\rightarrow$ Day30$50 \rightarrow$ Day20-50 $\rightarrow$ Day20-100 $\rightarrow$ Day30-100), the spectral intensity of rice roots showed regularity at $\mathrm{Cd}$ II $214.44 \mathrm{~nm}$, Cd II $226.50 \mathrm{~nm}$ and Cd I $228.80 \mathrm{~nm}$. In the non-CK group, obvious spectral peaks appeared at the spectral lines of $\mathrm{Cd}$, and the intensity of spectral lines showed a trend of gradually increasing according to the specific concentration sequence. It was shown that the LIBS spectral lines were consistent with the cadmium concentration sequence analyzed by ICP-OES. The comparison of spectral intensities at Cd II $214.44 \mathrm{~nm}$, Cd II $226.50 \mathrm{~nm}$ and Cd I $228.80 \mathrm{~nm}$ for different cadmium concentration samples is shown in Fig. $4 \mathrm{~b}, \mathrm{~d}$, f. Under the same time conditions, with the increase of cadmium concentration, the line intensity of rice roots showed a gradually increasing trend. The trend was applicable to Cd II $214.44 \mathrm{~nm}$, Cd II $226.50 \mathrm{~nm}$ and Cd I $228.80 \mathrm{~nm}$. The results indicates that the accumulation of cadmium in roots is strongly related to the spectral values of the three Cd lines (Cd II $214.44 \mathrm{~nm}, \mathrm{Cd}$ II $226.50 \mathrm{~nm}$ and Cd I $228.80 \mathrm{~nm}$ ). The three $\mathrm{Cd}$ lines can be used as characteristic spectral lines for cadmium detection in rice roots.

\section{SEM/EDS analysis}

When spectrum was collected, each position in samples was continuously ablated 5 times with a laser pulse at a frequency of $1 \mathrm{~Hz}$, an ablation pit was finally formed. To obtain the microscopic morphology, SEM/EDS was
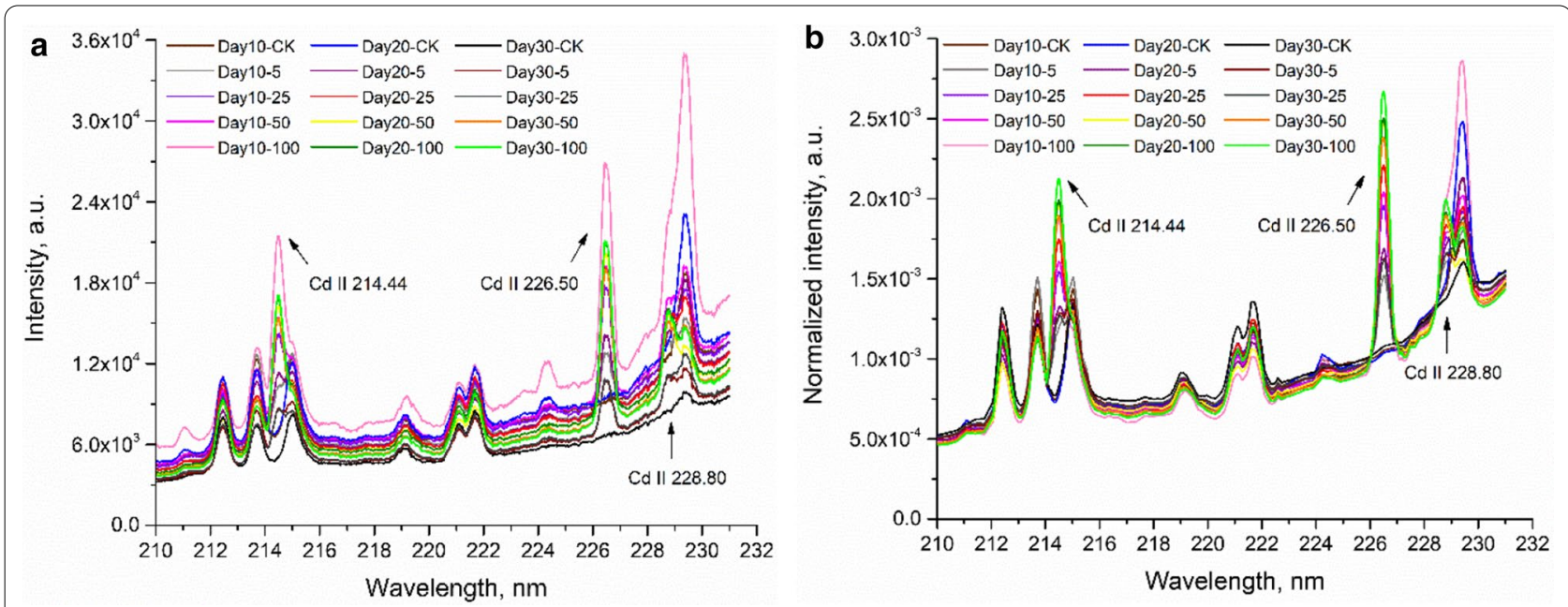

Fig. 3 Average spectra of root samples with different cadmium concentrations. a Average raw spectra; $\mathbf{b}$ average spectra after pretreatment 


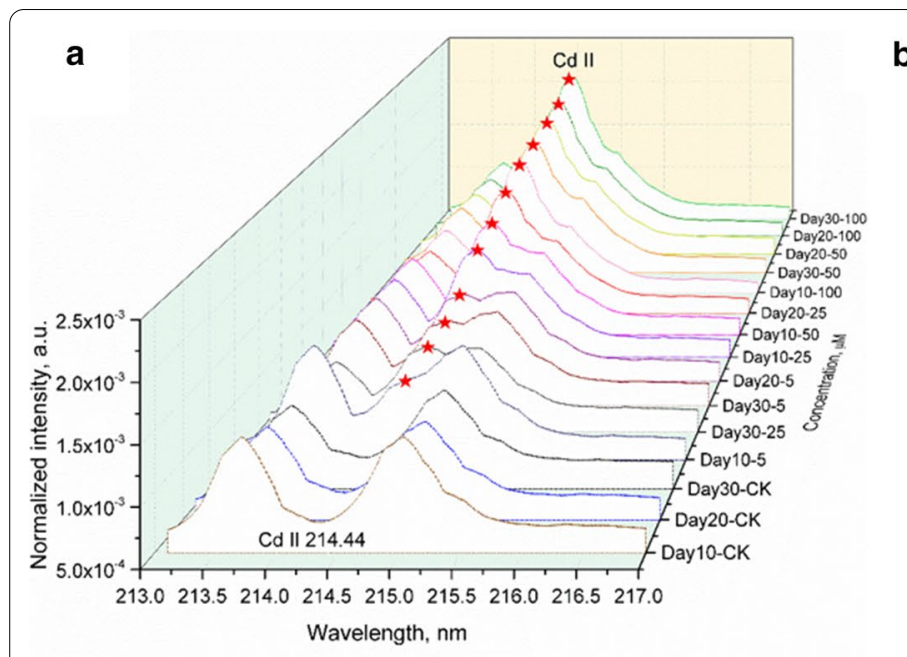

b
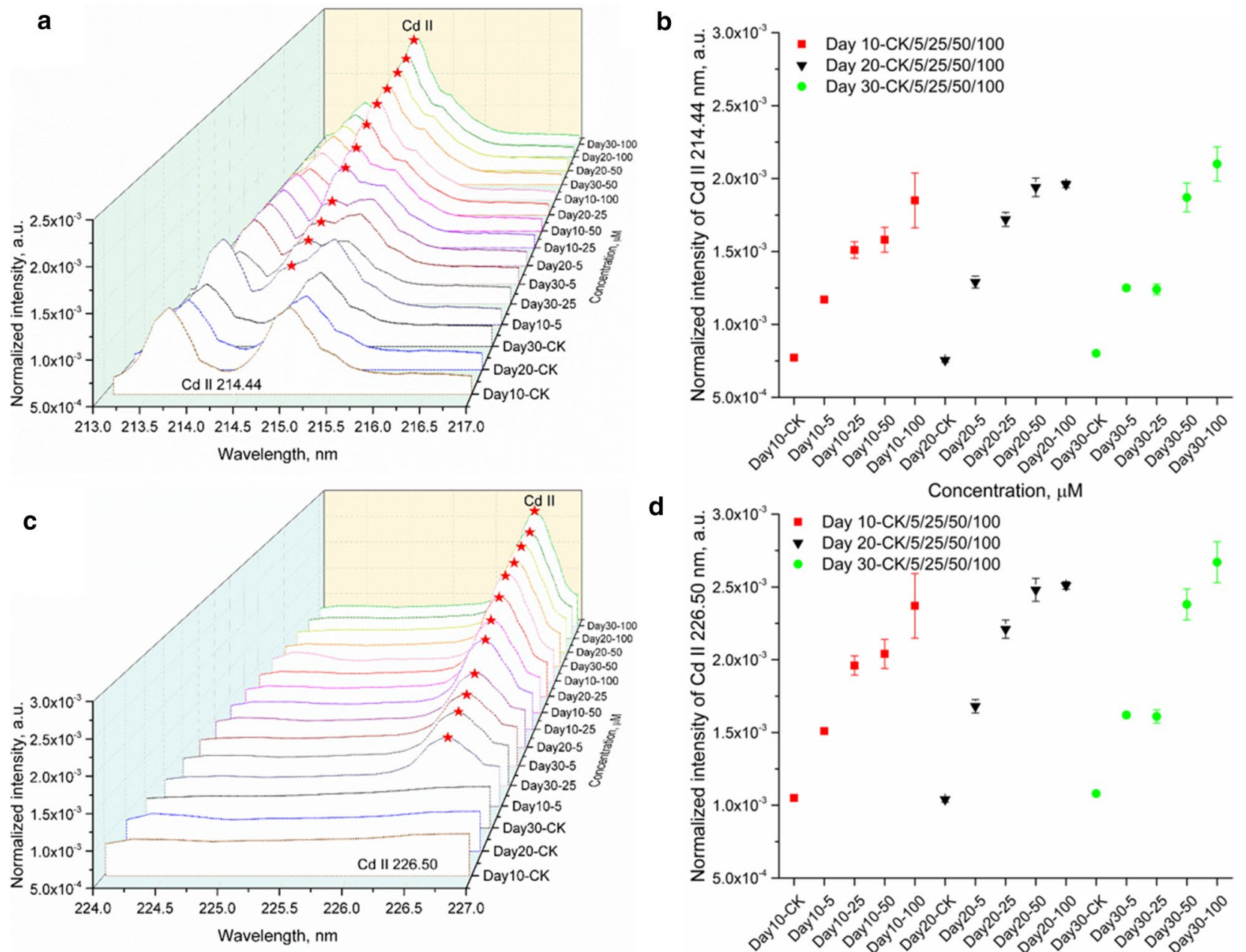

d

Concentration, $\mu \mathrm{M}$
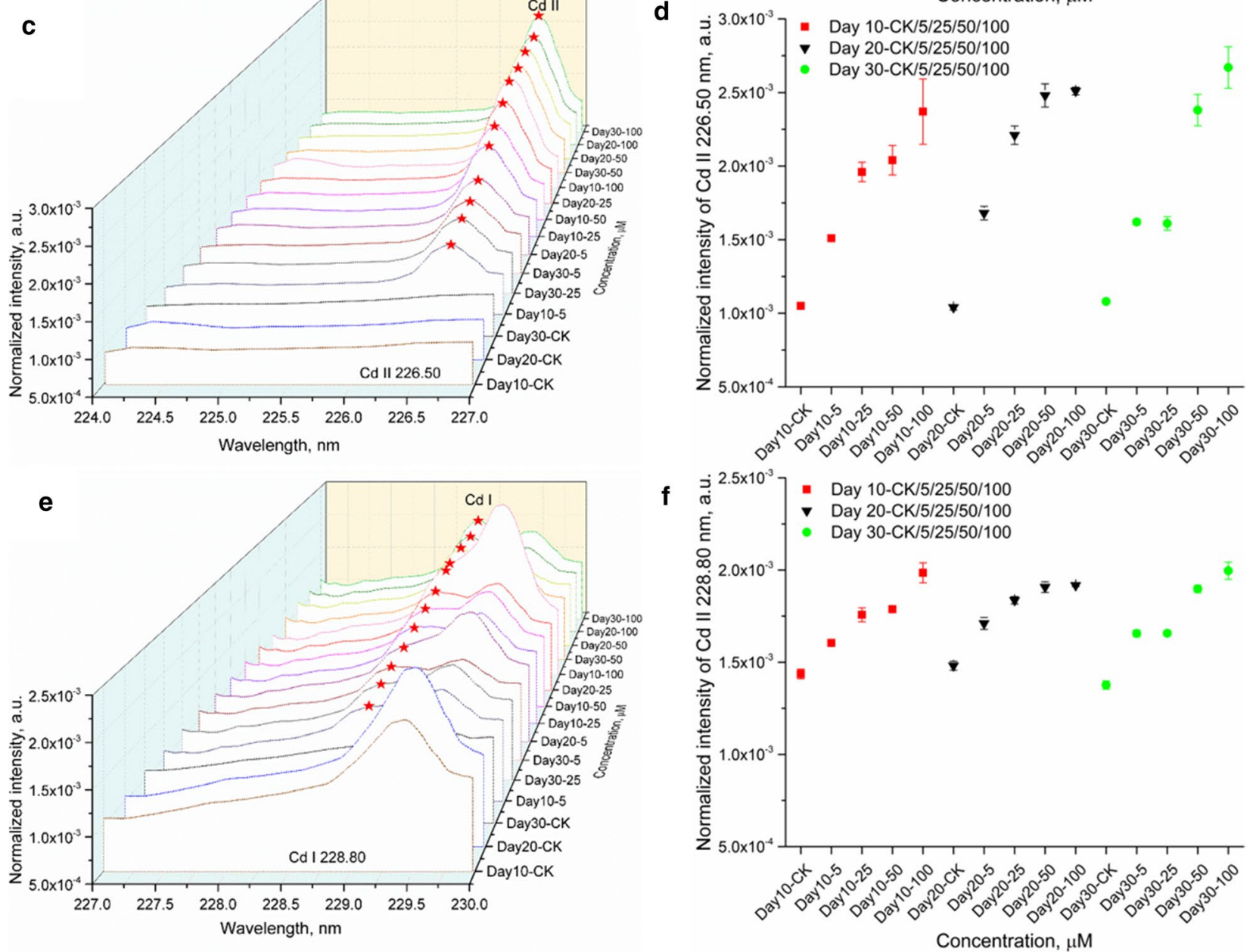

Fig. 4 Average spectra after pretreatment of root samples with different cadmium concentrations. Comparison of rice root spectral intensities with different cadmium concentrations at Cd II $214.44 \mathrm{~nm}, \mathrm{Cd}$ || $226.50 \mathrm{~nm}$ and Cd I $228.80 \mathrm{~nm}$. a Spectral intensities in the range of 213.00-217.00 nm; b comparison of spectral intensities at Cd II $214.44 \mathrm{~nm}$; c spectral intensities in the range of 224.00-227.00 nm; d comparison of spectral intensities at Cd II $226.50 \mathrm{~nm}$; e spectral intensities in the range of 227.00-230.00 nm; f comparison of spectral intensities at Cd I $228.80 \mathrm{~nm}$ 
applied to analyze surface morphology and element distribution information of ablation pit. A rectangular frame that encloses the ablation pit was selected as the region of interest. 15 rice root tablets with different cadmium concentrations were used for SEM/EDS analysis in the experiment. In this paper, the sample of Day30-100 is taken as an example to describe surface morphology and cadmium distribution of an ablation pit (Fig. 5). The ablation pit had a contour that is approximately circular (about $700 \mu \mathrm{m}$ in diameter) and was concave downward in the middle. The formation of the morphology was due to the small loss of samples when the sample was continuously ablated by laser pulse. Due to laser ablation, the surface of ablation pit area was uneven and cracked, and has attached sample fragments. Compared with the ablation pit, the surface of the surrounding area is relatively flat and firm. SEM/EDS shows the distribution of cadmium in the region of interest in red, where the shade of the color represents the amount. It can be found that for ablation pits, the red at the edge is darker than the red at the middle position. We suspected that the difference in cadmium distribution was due to more samples at the center of the ablative pit being ablated by laser.

SEM/EDS scan results of the root tablets showed the elemental composition of the sample and the relative content of each element, which was expressed in weight percent. The main components of the sample were $\mathrm{O}, \mathrm{C}$ and $\mathrm{N}$, accounting for about $90 \%$, followed by elements such as $\mathrm{Na}, \mathrm{Cl}, \mathrm{Si}$ and $\mathrm{K}$, accounting for about $10 \%$, and the remaining elements $\mathrm{Mg}, \mathrm{Ca}$ and $\mathrm{Cd}$ accounted for a very small proportion, about $1 \%$, which are shown in Table 2. Under the same time conditions, the Cd content in roots showed an increasing trend with the increase of cadmium concentration. No cadmium was found in the CK group (Day10-CK, Day20-CK, Day30-CK). The sample of Day30-100 had the highest content of $\mathrm{Cd}$, which was $0.32 \%$.

The correlation analysis was conducted on LIBS spectral data (Cd II $214.44 \mathrm{~nm}$, Cd II $226.50 \mathrm{~nm}$ and Cd I $228.80 \mathrm{~nm}$ ) and the cadmium weight percentage obtained by SEM/EDS, which were used to obtain the correlation between LIBS and SEM/EDS methods. According to the Shapiro-Wilk test, cadmium weight percentage and LIBS intensity data were in a normal distribution $(P>0.05)$. Pearson correlation analysis was used to evaluate the relationship between EDS and LIBS line intensity. A significant positive correlation was found between SEM/ EDS and LIBS intensity, $r_{214.44}=0.880, r_{226.50}=0.880$, $r_{228.80}=0.895, P<0.001$.

SEM/EDS was first used as a complementary technology to the LIBS method to provide microscopic information about ablation pits. SEM/EDS analyses of root tablets successfully reflected surface morphology, elemental composition and element distribution of cadmium in the ablation pit.

\section{Quantitative analysis of cadmium \\ Univariate analysis of $C d$ spectral lines}

LIBS spectrum can reflect the difference of cadmium concentration in different samples. To achieve accurate detection of heavy metals in rice roots, it is necessary to combine LIBS spectrum with quantitative analysis methods. Univariate analysis is a common quantitative analysis approach. It correlates the elemental content with the detection signal through a calibration curve, and then makes prediction. Univariate analysis was used to explore a

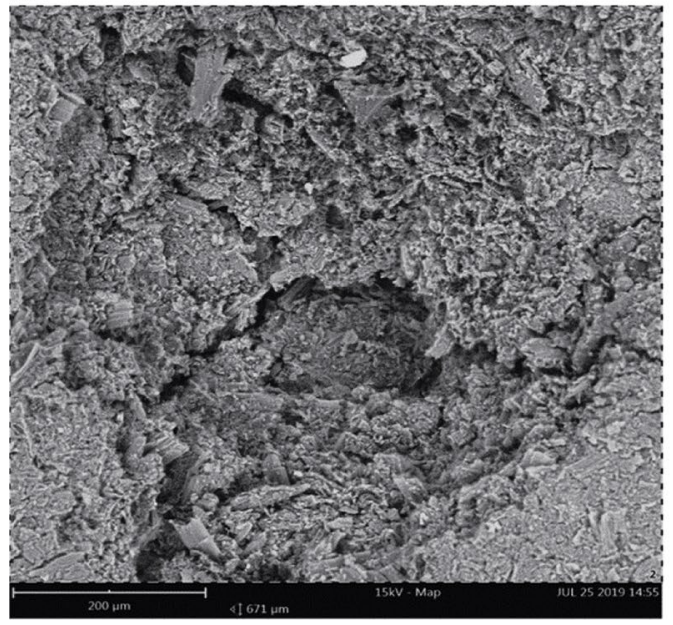

b

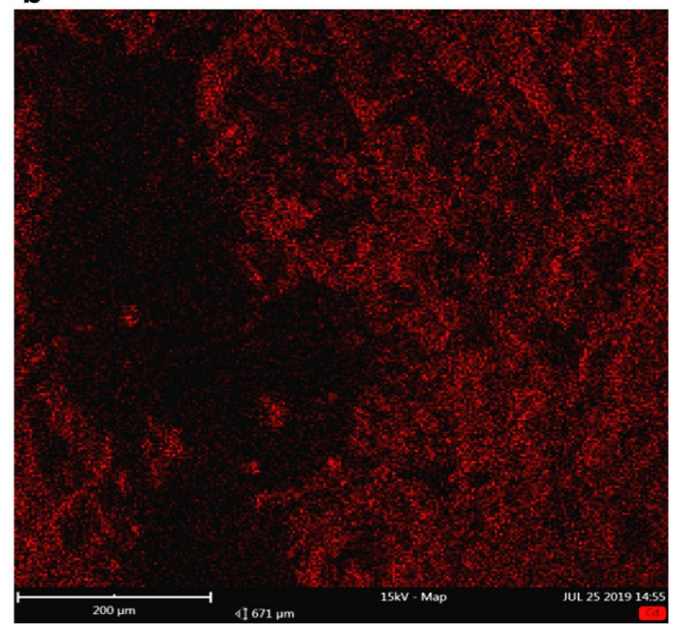

Fig. 5 SEM/EDS analysis of ablation pit in the sample of Day30-100. a Surface morphology; b distribution of cadmium 
Table 2 Element weight percentage obtained by EDS

\begin{tabular}{llllllllllll}
\hline Group & & $\mathrm{O}(\%)$ & $\mathrm{C}(\%)$ & $\mathrm{N}(\%)$ & $\mathrm{Na}(\%)$ & $\mathrm{Cl}(\%)$ & $\mathrm{Si}(\%)$ & $\mathrm{K}(\%)$ & $\mathrm{Mg}(\%)$ & $\mathrm{Ca}(\%)$ & $\mathrm{Cd}(\%)$ \\
\hline Day10 & $\mathrm{CK}$ & 72.79 & 14.46 & 3.84 & 2.76 & 2.67 & 1.53 & 1.42 & 0.31 & 0.22 & 0 \\
& 5 & 71.54 & 13.82 & 3.98 & 3.44 & 2.63 & 2.42 & 1.58 & 0.28 & 0.20 & 0.10 \\
& 25 & 72.20 & 14.67 & 3.63 & 2.95 & 2.53 & 1.80 & 1.51 & 0.33 & 0.25 & 0.15 \\
& 50 & 70.53 & 14.43 & 4.15 & 3.35 & 2.44 & 1.91 & 1.84 & 0.60 & 0.45 & 0.29 \\
& 100 & 70.23 & 14.35 & 3.57 & 3.45 & 2.39 & 2.35 & 2.22 & 0.63 & 0.53 & 0.28 \\
Day20 & $\mathrm{CK}$ & 73.14 & 15.74 & 2.97 & 2.32 & 2.23 & 1.93 & 1.28 & 0.24 & 0.14 & 0 \\
& 5 & 73.98 & 14.89 & 2.88 & 2.64 & 2.31 & 1.60 & 1.20 & 0.28 & 0.12 & 0.09 \\
& 25 & 73.59 & 15.24 & 2.59 & 2.27 & 2.22 & 2.13 & 1.30 & 0.24 & 0.21 & 0.20 \\
& 50 & 75.30 & 14.80 & 2.58 & 2.23 & 2.02 & 1.42 & 0.95 & 0.27 & 0.22 & 0.20 \\
& 100 & 73.97 & 14.86 & 2.62 & 2.41 & 2.30 & 1.78 & 1.32 & 0.27 & 0.26 & 0.20 \\
Day30 & $\mathrm{CK}$ & 75.52 & 15.53 & 2.42 & 2.03 & 1.83 & 1.24 & 0.83 & 0.29 & 0.29 & 0 \\
& 5 & 74.80 & 14.61 & 2.65 & 2.40 & 2.11 & 1.54 & 1.34 & 0.25 & 0.17 & 0.12 \\
& 25 & 75.05 & 15.83 & 2.48 & 1.85 & 1.68 & 1.44 & 0.86 & 0.39 & 0.22 & 0.20 \\
& 50 & 76.05 & 14.83 & 2.08 & 1.81 & 1.79 & 1.54 & 1.08 & 0.33 & 0.30 & 0.19 \\
& 100 & 74.38 & 14.48 & 2.36 & 2.08 & 1.96 & 1.80 & 1.47 & 0.64 & 0.51 & 0.32 \\
\hline
\end{tabular}

the correlation between $\mathrm{Cd}$ spectral lines and cadmium content in rice roots.

With Cd II $214.44 \mathrm{~nm}, \mathrm{Cd}$ II $226.50 \mathrm{~nm}$ and Cd I $228.80 \mathrm{~nm}$ as input and reference cadmium content obtained by ICP-OES as output, univariate models of cadmium content in rice roots were established, respectively, to compare fitting effects of different $\mathrm{Cd}$ spectral lines. Table 3 shows the univariable analysis results based on $\mathrm{Cd}$ spectral lines under the conditions of raw spectra and pretreatment. As for raw spectra, compared with other Cd spectral lines, Cd I $228.80 \mathrm{~nm}$ has poor correlation with $\mathrm{Cd}$ content due to baseline drift. From the results, it can be seen that the modeling effect after pretreatment are better than that of raw spectra, especially for Cd I $228.80 \mathrm{~nm}, R_{\mathrm{p}}$ is increased from 0.6529 to 0.9626 . Conclusively, the spectral lines of Cd II $214.44 \mathrm{~nm}$, Cd II $226.50 \mathrm{~nm}$ and Cd I $228.80 \mathrm{~nm}$ have good correlation with cadmium in rice roots. We can see from the results that, Cd II $226.50 \mathrm{~nm}$ after pretreatment has the best prediction effect on cadmium with highest $R$ and lowest RMSE $\left(R_{\mathrm{c}}=0.9840, \quad \mathrm{RMSEC}=28.1 \quad \mathrm{mg} / \mathrm{kg}, \quad R_{\mathrm{p}}=0.9794\right.$, $\mathrm{RMSEP}=33.2 \mathrm{mg} / \mathrm{kg}$ ).

\section{Univariate analysis of characteristic input variables}

We also used a variety of fitting methods including linear, logarithmic, and polynomial to mine the relationship between Cd spectral lines (Cd II $214.44 \mathrm{~nm}$, Cd II $226.50 \mathrm{~nm}$, and Cd I $228.80 \mathrm{~nm}$ ) and Cd content in rice roots, and proposed characteristic input variables about $\mathrm{Cd}$. We performed logarithmic and polynomial fitting based on the intensity of different $\mathrm{Cd}$ spectral lines $\left(I_{214.44 \mathrm{~nm}}, I_{226.50 \mathrm{~nm}}\right.$ and $\left.I_{228.80 \mathrm{~nm}}\right)$, and obtained 6 feature input variables. In addition, the combination of different Cd spectral line intensities $\left(I_{214.44 \mathrm{~nm}}+I_{226.50 \mathrm{~nm}}\right.$, $I_{226.50 \mathrm{~nm}}+I_{228.80 \mathrm{~nm}}, I_{214.44 \mathrm{~nm}}+I_{228.80 \mathrm{~nm}}, I_{214.44 \mathrm{~nm}}+I_{226.50}$ $\mathrm{nm}+I_{228.80 \mathrm{~nm}}$ ) was used as input to perform multiple linear regression, and 4 characteristic input variables were obtained.

Table 3 Univariable analysis results based on Cd spectral lines

\begin{tabular}{|c|c|c|c|c|c|}
\hline \multirow[t]{2}{*}{ Pretreatment methods } & \multirow[t]{2}{*}{ Wavelength (nm) } & \multicolumn{2}{|c|}{ Calibration set } & \multicolumn{2}{|c|}{ Prediction set } \\
\hline & & $R_{\mathrm{c}}$ & RMSEC (mg/kg) & $R_{\mathrm{p}}$ & $\operatorname{RMSEP}(\mathrm{mg} / \mathrm{kg})$ \\
\hline \multirow[t]{3}{*}{ Raw } & 214.44 & 0.8812 & 74.6 & 0.9295 & 61.5 \\
\hline & 226.50 & 0.8703 & 77.8 & 0.9222 & 65.0 \\
\hline & 228.80 & 0.5495 & 133.0 & 0.6529 & 128.0 \\
\hline \multirow[t]{3}{*}{ After pretreatment ${ }^{a}$} & 214.44 & 0.9822 & 29.5 & 0.9786 & 33.7 \\
\hline & 226.50 & 0.9840 & 28.1 & 0.9794 & 33.2 \\
\hline & 228.80 & 0.9548 & 46.8 & 0.9626 & 46.4 \\
\hline
\end{tabular}

Bold emphasis: the optimal model for given conditions

a Pretreatment methods: MAD, WT and area normalization 
Table 4 Univariable analysis results based on characteristic input variables

\begin{tabular}{|c|c|c|c|c|c|c|c|}
\hline \multirow[t]{2}{*}{ Pretreatment methods } & \multirow[t]{2}{*}{ Wavelength (nm) } & \multirow[t]{2}{*}{ Model } & \multirow{2}{*}{$\begin{array}{l}\text { Determination } \\
\text { coefficient }\end{array}$} & \multicolumn{2}{|c|}{ Calibration set } & \multicolumn{2}{|c|}{ Prediction set } \\
\hline & & & & $R_{\mathrm{c}}$ & RMSEC (mg/kg) & $R_{\mathrm{p}}$ & $\operatorname{RMSEP}(\mathrm{mg} / \mathrm{kg})$ \\
\hline \multirow[t]{10}{*}{ Raw } & 214.44 & Logarithmic & 0.9101 & 0.8995 & 68.9 & 0.9140 & 64.7 \\
\hline & & Polynomial & 0.9222 & 0.9116 & 64.8 & 0.9248 & 60.7 \\
\hline & 226.50 & Logarithmic & 0.9044 & 0.8931 & 70.9 & 0.9081 & 66.9 \\
\hline & & Polynomial & 0.9168 & 0.8996 & 68.8 & 0.9160 & 64.3 \\
\hline & 228.80 & Logarithmic & 0.6473 & 0.6336 & 122.0 & 0.6336 & 124.0 \\
\hline & & Polynomial & 0.6833 & 0.6800 & 116.0 & 0.6290 & 124.0 \\
\hline & $214.44+226.50$ & Linear & 0.9406 & 0.9329 & 56.7 & 0.9479 & 54.8 \\
\hline & $226.50+228.80$ & Linear & 0.9712 & 0.9738 & 35.8 & 0.9610 & 45.9 \\
\hline & $214.44+228.80$ & Linear & 0.9709 & 0.9734 & 36.0 & 0.9614 & 46.0 \\
\hline & $214.44+226.50+228.80$ & Linear & 0.9712 & 0.9738 & 35.8 & 0.9612 & 45.9 \\
\hline \multirow[t]{10}{*}{ After pretreatment } & 214.44 & Logarithmic & 0.9805 & 0.9622 & 42.9 & 0.9566 & 46.7 \\
\hline & & Polynomial & 0.9922 & 0.9833 & 28.7 & 0.9821 & 31.1 \\
\hline & 226.50 & Logarithmic & 0.9834 & 0.9683 & 39.3 & 0.962 & 43.9 \\
\hline & & Polynomial & 0.9924 & 0.9844 & 27.7 & 0.9818 & 31.4 \\
\hline & 228.80 & Logarithmic & 0.9759 & 0.9485 & 49.9 & 0.9521 & 50.8 \\
\hline & & Polynomial & 0.9815 & 0.9563 & 46.1 & 0.9734 & 42.6 \\
\hline & $214.44+226.50$ & Linear & 0.9922 & 0.9856 & 26.7 & 0.9796 & 33.2 \\
\hline & $226.50+228.80$ & Linear & 0.9926 & 0.9868 & 25.5 & 0.9793 & 32.4 \\
\hline & $214.44+228.80$ & Linear & 0.9922 & 0.9851 & 27.1 & 0.9779 & 33.1 \\
\hline & $214.44+226.50+228.80$ & Linear & 0.9929 & 0.9878 & 24.5 & 0.9793 & 32.6 \\
\hline
\end{tabular}

Bold emphasis: the optimal model for given conditions

Table 4 shows the univariate analysis results with above characteristic input variables as input. Analyzing the results of raw spectra, we can get the following conclusions. For a single $\mathrm{Cd}$ spectral line, the effect of polynomial-based characteristic input variables is better than logarithmic. Compared with a single $\mathrm{Cd}$ spectral line, the combination of multiple $\mathrm{Cd}$ spectral lines has a better determination coefficient, and the univariate model based on the corresponding characteristic input variables has a better prediction effect. For raw spectra, the univariable analysis based on the characteristic input variable of multiple linear fitting of $I_{214.44} \mathrm{~nm}+I_{228.80} \mathrm{~nm}$ has achieved the best prediction effect, where $R_{\mathrm{p}}$ reached 0.9614 and RMSEP was $46.0 \mathrm{mg} / \mathrm{kg}$. Compared with raw spectra, it can be found that the model established after pretreatment has better results, with higher $R$ and lower RMSE, which is consistent with the results of univariate analysis based on $\mathrm{Cd}$ spectral lines. For the pretreatment spectra, the univariate analysis based on the characteristic input variable of polynomial fitting of $I_{214.44 \mathrm{~nm}}$ has achieved the best modeling effect, where $R_{\mathrm{p}}$ reached 0.9821 and RMSEP was $31.1 \mathrm{mg} / \mathrm{kg}$. Based on the above results, we can find that compared with univariable analysis based on $\mathrm{Cd}$ spectral lines, the univariable analysis based on characteristic input variables has better modeling effect.

\section{Multivariate analysis}

The monochromator collected spectral information in the range of 210.01-231.99 $\mathrm{nm}$ and obtained 1024 variables. Compared with univariate analysis, multivariate analysis usually contains more variables. It can extract more useful information from a large amount of data for modeling and prediction. The multivariate analysis method is beneficial to eliminate sample matrix effects, background influences, spectral line interference and point-to-point fluctuations, which can effectively improve the modeling effect. Three $\mathrm{Cd}$ spectral lines (Cd II 214.44 nm, Cd II $226.50 \mathrm{~nm}$, and Cd I 228.80) and full spectrum were used as inputs. PLSR, LS-SVM and ELM algorithms were, respectively, used to establish the cadmium quantitative detection model based on the raw spectra and the pretreatment spectra. Multivariate analysis results based on different variables are shown in Table 5. For raw spectra, PLSR and LS-SVM models have better effects, while ELM model has poor effects. After the pretreatment, the effects of the three models have been improved, of which ELM model has the most obvious improvement and becomes the model with the best effect. For Cd spectral lines after pretreatment, ELM model works best, $R_{\mathrm{c}}$ reached 0.9921 and RMSEC was $19.70 \mathrm{mg} / \mathrm{kg}, R_{\mathrm{p}}$ reached 0.9869 and 
Table 5 Multivariate analysis results based on different variables

\begin{tabular}{|c|c|c|c|c|c|c|c|}
\hline \multirow[t]{2}{*}{ Pretreatment methods } & \multirow[t]{2}{*}{ Variable (nm) } & \multirow[t]{2}{*}{ Model } & \multirow[t]{2}{*}{ Parameter ${ }^{a}$} & \multicolumn{2}{|c|}{ Calibration set } & \multicolumn{2}{|c|}{ Prediction set } \\
\hline & & & & $R_{c}$ & RMSEC (mg/kg) & $R_{p}$ & $\operatorname{RMSEP}(\mathrm{mg} / \mathrm{kg})$ \\
\hline \multirow[t]{6}{*}{ Raw } & \multirow[t]{3}{*}{$214.44+226.50+228.80$} & PLSR & 2 & 0.9708 & 37.7 & 0.9612 & 46.1 \\
\hline & & LS-SVM & $(588,390.13,86.94)$ & 0.9869 & 25.3 & 0.9743 & 38.6 \\
\hline & & ELM & 36 & 0.9511 & 48.6 & 0.9429 & 54.3 \\
\hline & \multirow[t]{3}{*}{ Full } & PLSR & 3 & 0.9778 & 33.0 & 0.9659 & 42.1 \\
\hline & & LS-SVM & $(1974.88,16,315.65)$ & 0.9923 & 19.5 & 0.9806 & 31.6 \\
\hline & & ELM & 28 & 0.9573 & 45.5 & 0.9557 & 49.4 \\
\hline \multirow[t]{6}{*}{ After pretreatment } & \multirow[t]{3}{*}{$214.44+226.50+228.80$} & PLSR & 2 & 0.9859 & 26.3 & 0.9791 & 32.4 \\
\hline & & LS-SVM & $(2026.25,151.09)$ & 0.9911 & 21.0 & 0.9828 & 29.4 \\
\hline & & ELM & 31 & 0.9921 & 19.7 & 0.9869 & 25.6 \\
\hline & \multirow[t]{3}{*}{ Full } & PLSR & 3 & 0.9863 & 26.0 & 0.9808 & 31.1 \\
\hline & & LS-SVM & $(767.71,35,346.51)$ & 0.9935 & 17.9 & 0.9837 & 28.7 \\
\hline & & ELM & 15 & 0.9943 & 16.8 & 0.9896 & 26.0 \\
\hline
\end{tabular}

Bold emphasis: the optimal model for given conditions

a Parameters of different models: the optimal number of latent variables (LVs) for PLSR, the bandwidth of kernel function (sig2) and the trade-off between the minimum model complexity and the minimum training error (gam) for LS-SVM, the number of hidden nodes for ELM.

RMSEP was $25.6 \mathrm{mg} / \mathrm{kg}$. For full spectrum after pretreatment, ELM model also achieved the best results, $R_{\mathrm{c}}$ reached 0.9943 and RMSEC was $16.80 \mathrm{mg} / \mathrm{kg}, R_{\mathrm{p}}$ reached 0.9896 and RMSEP was $26.0 \mathrm{mg} / \mathrm{kg}$. It is obvious that the multivariate analysis based on full spectrum is better than that based on Cd spectral lines.

\section{Univariate analysis vs multivariate analysis}

After univariate analysis and multivariate analysis, we obtained the optimal models under corresponding conditions. We compared the results of the above best models, and the relationship between the reference $\mathrm{Cd}$ content and prediction $\mathrm{Cd}$ content of different model is shown in Fig. 6. For univariable analysis, compared with $\mathrm{Cd}$ spectral lines, the model based on characteristic input variables has better prediction effect, in which the model based on the characteristic input variable of polynomial fitting of I214.44 nm obtained the best effect $\left(R_{\mathrm{c}}=0.9833\right.$, RMSEC $=28.7 \mathrm{mg} / \mathrm{kg}, R_{\mathrm{p}}=0.9821, \quad \mathrm{RMSEP}=31.1 \mathrm{mg} /$ $\mathrm{kg}$ ). For multivariate analysis, compared with the local spectral lines, the model based on the full spectrum has better prediction effect, in which ELM model has the best effect $\left(R_{\mathrm{c}}=0.9943, \quad \mathrm{RMSEC}=16.8 \mathrm{mg} / \mathrm{kg}\right.$, $R_{\mathrm{p}}=0.9896, \quad \mathrm{RMSEP}=26.0 \mathrm{mg} / \mathrm{kg}$ ). The multivariate analysis results of the full spectrum based on ELM model are superior to the univariate analysis based on the characteristic input variable of polynomial fitting of $I_{214.44} \mathrm{~nm}$. The results showed that compared with the univariate analysis, the multivariate analysis based on full spectrum had more advantages in the rapid detection of the heavy metal cadmium in roots. This is because the full spectrum contains all sensitive spectral lines and effective matrix information of cadmium, and the combination of spectral lines increases the prediction modeling information of cadmium. In addition, traditional methods take more than $150 \mathrm{~min}$ to achieve heavy metal detection for a sample, while the combination of LIBS technology and chemometrics takes less than 5 min. LIBS technology greatly reduces the time required to detect heavy metals in samples.

\section{Conclusions}

In this study, a method for quantitative detection of cadmium in rice roots using LIBS technology was introduced. The results indicated that cadmium accumulation of roots was strongly related to the LIBS spectral lines of Cd II $214.44 \mathrm{~nm}$, Cd II $226.50 \mathrm{~nm}$ and Cd I $228.80 \mathrm{~nm}$. SEM/EDS was successfully used for the first time to reflect the surface morphology, element composition and spatial elemental distribution of ablative pits. What is more, it has been proved that $\mathrm{Cd}$ spectral lines showed significant positive correlation with SEM/EDS analysis results, that is, $r_{214.44}=0.880, r_{226.50}=0.880$, $r_{228.80}=0.895, P<0.001$. The univariable analysis results based on Cd spectral lines showed that Cd II $214.44 \mathrm{~nm}$, Cd II $226.50 \mathrm{~nm}$ and Cd I $228.80 \mathrm{~nm}$ have good correlation with cadmium in rice roots. Cd II $226.50 \mathrm{~nm}$ after pretreatment has achieved the best prediction on cadmium, with $R_{\mathrm{p}}$ of 0.9794 and RMSEP of $33.2 \mathrm{mg} / \mathrm{kg}$. A variety of fitting methods including linear, logarithmic, and polynomial were used to propose characteristic input variables about $\mathrm{Cd}$. We can see from the results that the univariate analysis based on the characteristic input variable of polynomial fitting of $I_{214.44 \mathrm{~nm}}$ has achieved the 

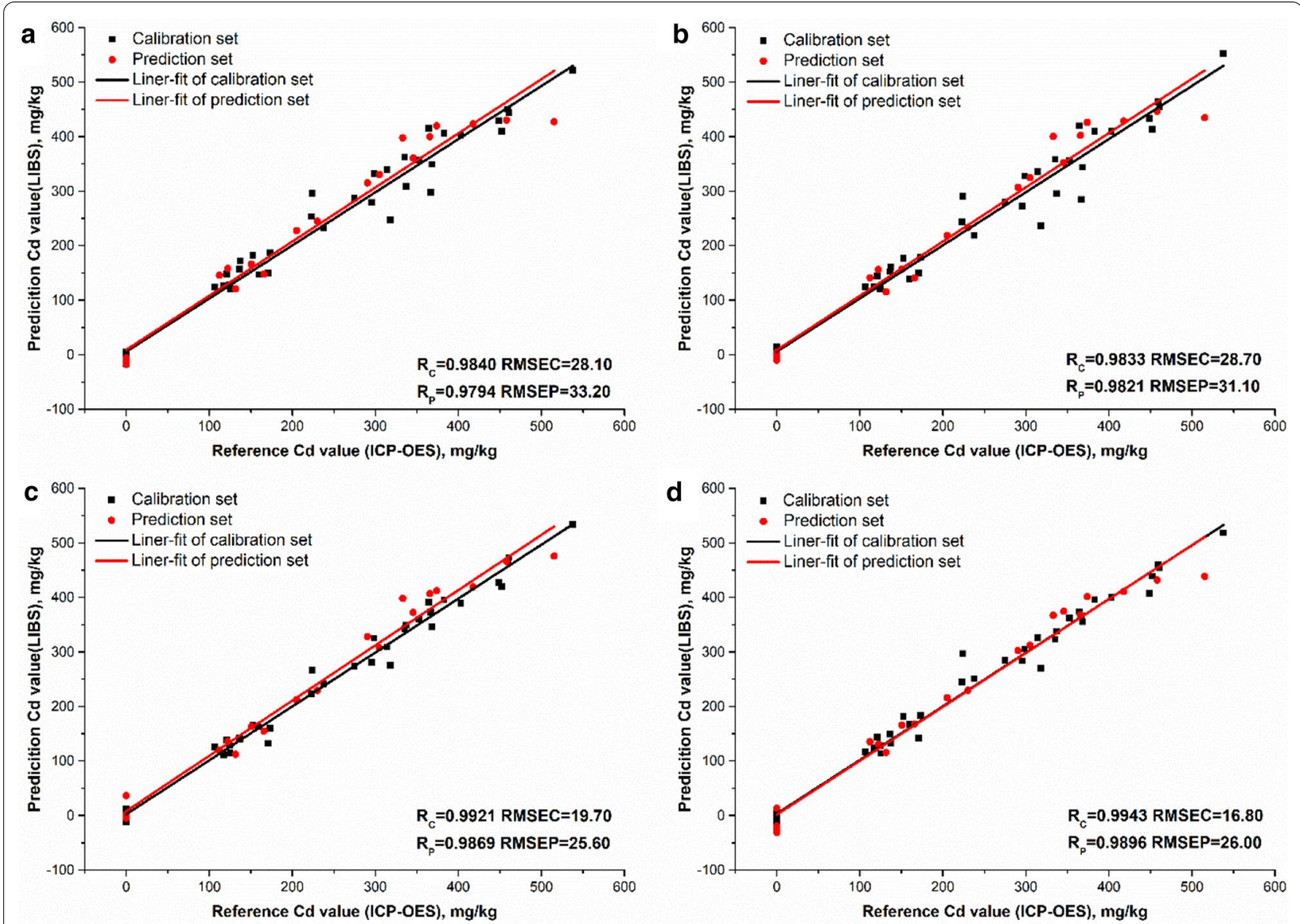

Fig. 6 Relationship between the reference Cd content and prediction Cd content of different models: a univariate analysis of Cd II $226.50 \mathrm{~nm}$ after pretreatment; $\mathbf{b}$ univariate analysis based on the characteristic input variable of polynomial fitting of $I_{214.44 \mathrm{~nm}}$ after pretreatment; $\mathbf{c}$ ELM model of three $\mathrm{Cd}$ spectral lines after pretreatment; $\mathbf{d}$ ELM model of full spectrum after pretreatment

best effect, where $R_{\mathrm{p}}$ reached 0.9821 and RMSEP was $31.1 \mathrm{mg} / \mathrm{kg}$. Besides univariate models, PLSR, LS-SVM and ELM were, respectively, used to establish quantitative detection model. The ELM model based on the full spectrum achieved the best results, with $R_{\mathrm{c}}$ reaching 0.9943 , RMSEC of $16.80 \mathrm{mg} / \mathrm{kg}, R_{\mathrm{p}}$ of 0.9896 , and RMSEP of $26.0 \mathrm{mg} / \mathrm{kg}$. It can be found that the multivariate analysis based on full spectrum is better than that based on $\mathrm{Cd}$ spectral lines. Compared with univariate analysis, the multivariate analysis based on full spectrum had more advantages for the rapid detection of cadmium content in rice roots. Compared with traditional methods (150 min), the quantitative detection method based on LIBS technology (less than $5 \mathrm{~min}$ ) greatly reduces the detection time of heavy metals. The present work indicated that LIBS has significant advantages in rapid and accurate detection of cadmium in rice roots. The research can help solve the problem that heavy metals in contaminated food is difficult to detect quickly and accurately, and provides theoretical support for timely detection of heavy metals in crop and food production.

\section{Abbreviations}

LIBS: Laser-induced breakdown spectroscopy; SEM/EDS: Scanning electron microscope/energy-dispersive X-ray spectrometer; PLSR: Partial least squares regression; LS-SVM: Least squares support vector machine; ELM: Extreme learning machine; AAS: Atomic absorption spectroscopy; ICP-OES: Inductively coupled plasma optical emission spectrometer; ICP-MS: Inductively coupled plasma with mass spectrometer; MAD: Median absolute deviation; WT: Wavelet transform; $R$ : Correlation coefficient; $R_{c}$ : Calibration set correlation coefficients; $R_{\mathrm{p}}$ : Prediction set correlation coefficients; RMSE: Root mean square error; RMSEC: Root mean square error of calibration; RMSEP: Root mean square error of prediction.

\section{Acknowledgements}

We thank Jiming Xu in College of Life Science, Zhejiang University for providing ICP-OES assay. We also thank Yuechao Liang, Chuanjie Zhang and Bo Wei of Phenom-Scientific for providing SEM/EDS assay.

\section{Authors' contributions}

FL and YH provided experimental equipment and test funds. WW designed experimental scheme, and was a major contributor in writing the manuscript. ZM collected the LIBS spectra. TS performed the experiments of ICP-OES. 
WK and WZ analyzed the data. All the authors read and approved the final manuscript.

\section{Funding}

This research was funded by Natural Science Foundation of China, grant number 61975174, Synergistic Innovation Center of Jiangsu Modern Agricultural Equipment and Technology, grant number 4091600021 and the Key Laboratory of Spectroscopy Sensing, Ministry of Agriculture and Rural Affairs, P.R. China, grant number 2018ZJUGP004.

\section{Availability of data and materials}

The datasets obtained and analyzed in the current study are available from the corresponding author on reasonable request.

\section{Declarations}

Ethics approval and consent to participate

Not applicable.

\section{Consent for publication}

Not applicable.

\section{Competing interests}

The authors declare that they have no competing interests.

\section{Author details}

${ }^{1}$ College of Biosystems Engineering and Food Science, Zhejiang University, 866 Yuhangtang Road, Hangzhou 310058, China. ${ }^{2}$ School of Agricultural Equipment Engineering, Jiangsu University, 301 Xuefu Road, Zhenjiang 212013, China. ${ }^{3}$ School of Information Engineering, Zhejiang A \& F University, 666 Wusu Street, Hangzhou 311300, China. ${ }^{4}$ Key Laboratory of Spectroscopy Sensing, Ministry of Agriculture and Rural Affairs, Hangzhou 310058, China.

Received: 24 January 2021 Accepted: 16 March 2021

Published online: 25 March 2021

\section{References}

1. Choppala G, Saifullah BN, Bibi S, labal M, Rengel Z, Kunhikrishnan A, Ashwath N, OkYS (2014) Cellular mechanisms in higher plants governing tolerance to cadmium toxicity. Crit Rev Plant Sci 33(5):374-391. https:// doi.org/10.1080/07352689.2014.903747

2. Wang F, Min W, Zhouping L, Yan S, Tiqian H, Yaoyao Y, Ning G, Junwei S, Cheng Z (2015) Different responses of low grain-Cd-accumulating and high grain-Cd-accumulating rice cultivars to $\mathrm{Cd}$ stress. Plant Physiol Biochem 96:261-269. https://doi.org/10.1016/j.plaphy.2015.08.001

3. Shahid M, Dumat C, Khalid S, Niazi NK, Antunes PMC (2017) Cadmium bioavailability, uptake, toxicity and detoxification in soil-plant system. In: de Voogt P (ed) Reviews of environmental contamination and toxicology. Springer International Publishing, Cham, pp 73-137

4. Ackova DG (2018) Heavy metals and their general toxicity on plants. Plant Sci Today 5(1):14-18. https://doi.org/10.14719/pst.2018.5.1.355

5. Chiao WT, Yu CH, Juang KW (2019) The variation of rice cultivars in Cd toxicity and distribution of the seedlings and their root histochemical examination. Paddy Water Environ 17(4):605-618. https://doi.org/10. 1007/s10333-018-00690-2

6. Cui J, Liu T, Li F, Yi J, Liu C, Yu H (2017) Silica nanoparticles alleviate cadmium toxicity in rice cells: mechanisms and size effects. Environ Pollut 228:363-369. https://doi.org/10.1016/j.envpol.2017.05.014

7. Gao L, Jiadong C, Ruijie C, Hubo L, Hongfei L, Longxing T, Jie X (2016) Comparison on cellular mechanisms of iron and cadmium accumulation in rice: prospects for cultivating Fe-rich but Cd-free rice. Rice 9:39. https:// doi.org/10.1186/s12284-016-0112-7

8. Nawrot TS, Staessen JA, Roels HA, Munters E, Cuypers A, Richart T, Ruttens A, Smeets K, Clijsters H, Vangronsveld J (2010) Cadmium exposure in the population: from health risks to strategies of prevention. Biometals 23(5):769-782. https://doi.org/10.1007/s10534-010-9343-z
9. Clemens S, Simm C (2003) Schizosaccharomyces pombe as a model for metal homeostasis in plant cells: the phytochelatin-dependent pathway is the main cadmium detoxification mechanism. N Phytol 159(2):323330. https://doi.org/10.1046/j.1469-8137.2003.00811.x

10. Li P, Ge Y, Wu L, Shen L, Tan W, Luo Y (2011) Uptake and translocation of cadmium and its physiological effects in two rice cultivars differed in grain cadmium concentration. Chin J Rice Sci 25(3):291-296. https://doi. org/10.3969/j.issn.1001-7216.2011.03.010

11. Yang $Y$, Jiangmin $C$, Qina $H$, Shaoqing $T$, Jianlong W, Peisong $H$, Guosheng $\mathrm{S}$ (2018) Can liming reduce cadmium (Cd) accumulation in rice (Oryza sativa) in slightly acidic soils? A contradictory dynamic equilibrium between Cd uptake capacity of roots and Cd immobilisation in soils. Chemosphere 193:547-556. https://doi.org/10.1016/j.chemosphere.2017. 11.061

12. Chen J, Zou W, Meng L, Fan X, Xu G, Ye G (2019) Advances in the uptake and transport mechanisms and QTLs mapping of cadmium in rice. Int J Mol Sci 20(14):17. https://doi.org/10.3390/ijms20143417

13. Liu F, Ye L, Peng J, Song K, Shen T, Zhang C, He Y (2018) Fast detection of copper content in rice by laser-induced breakdown spectroscopy with uni- and multivariate analysis. Sensors. https://doi.org/10.3390/s1803 0705

14. Ouyang Q, Tu L, Zhang Y, Chen H, Fan Y, Tu Y, Li Y, Sun Y (2020) Construction of a smart nanofluidic sensor through a redox reaction strategy for high-performance carbon monoxide sensing. Anal Chem 92(22):1494714952. https://doi.org/10.1021/acs.analchem.0c02424

15. Wang P, Yang H, Liu C, Qiu M, Ma X, Mao Z, Sun Y, Liu Z (2021) Recent advances in the development of activatable multifunctional probes for in vivo imaging of caspase-3. Chin Chem Lett 32(1):168-178. https://doi. org/10.1016/j.cclet.2020.11.056

16. Zhang R, Xu Y, Zhang Y, Kim HS, Sharma A, Gao J, Yang G, Kim JS, Sun Y (2019) Rational design of a multifunctional molecular dye for dual-modal NIR-II/photoacoustic imaging and photothermal therapy. Chem Sci 10(36):8348-8353. https://doi.org/10.1039/C9SC03504D

17. Peng J, Liu F, Zhou F, Song K, Zhang C, Ye L, He Y (2016) Challenging applications for multi-element analysis by laser-induced breakdown spectroscopy in agriculture: a review. TrAC. Trends Anal Chem 85:260272. https://doi.org/10.1016/j.trac.2016.08.015

18. Nicolodelli G, Cabral J, Menegatti CR, Marangoni B, Senesi GS (2019) Recent advances and future trends in LIBS applications to agricultural materials and their food derivatives: an overview of developments in the last decade (2010-2019). Part I. Soils and fertilizers. TrAC. Trends Anal Chem 115:70-82. https://doi.org/10.1016/j.trac.2019.03.032

19. Senesi GS, Dell'Aglio M, Gaudiuso R, De Giacomo A, Zaccone C, De Pascale O, Miano TM, Capitelli M (2009) Heavy metal concentrations in soils as determined by laser-induced breakdown spectroscopy (LIBS), with special emphasis on chromium. Environ Res 109(4):413-420. https://doi. org/10.1016/j.envres.2009.02.005

20. Gondal MA, Hussain T, Yamani ZH, Baig MA (2009) On-line monitoring of remediation process of chromium polluted soil using LIBS. J Hazard Mater 163(2-3):1265-1271. https://doi.org/10.1016/j.jhazmat.2008.07.127

21. Liu F, Shen T, Kong W, Peng J, Zhang C, Song K, Wang W, Zhang C, He Y (2018) Quantitative analysis of cadmium in tobacco roots using laserinduced breakdown spectroscopy with variable index and chemometrics. Front Plant Sci. https://doi.org/10.3389/fpls.2018.01316

22. Wu D, Meng L, Yang L, Wang J, Fu X, Du X, Li S, He Y, Huang L (2019) Feasibility of laser-induced breakdown spectroscopy and hyperspectral imaging for rapid detection of thiophanate-methyl residue on mulberry fruit. Int J Mol Sci 20(8):14. https://doi.org/10.3390/ijms20082017

23. Yang P, Zhou R, Zhang W, Yi R, Tang S, Guo L, Hao Z, Li X, Lu Y, Zeng X (2019) High-sensitivity determination of cadmium and lead in rice using laser-induced breakdown spectroscopy. Food Chem 272:323-328. https://doi.org/10.1016/j.foodchem.2018.07.214

24. Liu F, Ye L, Peng J, Song K, Shen T, Zhang C, He Y (2018) Fast detection of copper content in rice by laser-induced breakdown spectroscopy with uni- and multivariate analysis. Sensors 18(3):705

25. Jabbar A, Akhtar M, Ali A, Mehmood S, Iftikhar S, Baig MA (2019) Elemental composition of rice using calibration free laser induced breakdown spectroscopy. Optoelectron Lett 15(1):57-63. https://doi.org/10.1007/ s11801-019-8099-0

26. Peng J, He Y, Jiang J, Zhao Z, Zhou F, Liu F (2019) High-accuracy and fast determination of chromium content in rice leaves based on collinear 
dual-pulse laser-induced breakdown spectroscopy and chemometric methods. Food Chem 295:327-333. https://doi.org/10.1016/j.foodchem 2019.05.119

27. Peng J, He Y, Zhao Z, Jiang J, Zhou F, Liu F, Shen T (2019) Fast visualization of distribution of chromium in rice leaves by re-heating dual-pulse laserinduced breakdown spectroscopy and chemometric methods. Environ Pollut 252:1125-1132. https://doi.org/10.1016/j.envpol.2019.06.027

28. Dallagnol LJ, Rodrigues FA, DaMatta FM, Mielli MVB, Pereira SC (2011) Deficiency in silicon uptake affects cytological, physiological, and biochemical events in the rice-bipolaris oryzae interaction. Phytopathology 101(1):92-104. https://doi.org/10.1094/phyto-04-10-0105

29. Kucukkaya Eren S, Uzunoglu E, Sezer B, Yilmaz Z, Boyaci IH (2018) Mineral content analysis of root canal dentin using laser-induced breakdown spectroscopy. Restorative Dent Endodontics 43(1):11. https://doi.org/10. 5395/rde.2018.43.e11
30. Peng J, Song K, Zhu H, Kong W, Liu F, Shen T, He Y (2017) Fast detection of tobacco mosaic virus infected tobacco using laser-induced breakdown spectroscopy. Sci Rep. https://doi.org/10.1038/srep44551

31. Peng J, Liu F, Shen T, Ye L, Kong W, Wang W, Liu X, He Y (2018) Comparative study of the detection of chromium content in rice leaves by $532 \mathrm{~nm}$ and $1064 \mathrm{~nm}$ laser-induced breakdown spectroscopy. Sensors. https:// doi.org/10.3390/s18020621

32. Kong W, Zhang C, Huang W, Liu F, He Y (2018) Application of hyperspectral imaging to detect sclerotinia sclerotiorum on oilseed rape stems. Sensors. https://doi.org/10.3390/s18010123

\section{Publisher's Note}

Springer Nature remains neutral with regard to jurisdictional claims in published maps and institutional affiliations.

\section{Submit your manuscript to a SpringerOpen ${ }^{\circ}$ journal and benefit from:}

- Convenient online submission

- Rigorous peer review

- Open access: articles freely available online

- High visibility within the field

- Retaining the copyright to your article

Submit your next manuscript at $\boldsymbol{\nabla}$ springeropen.com 